\title{
Effects of Ocean Tide Load on Vertical Crustal Deformation in Northeastern Margin of Qinghai Tibet Plateau
}

\author{
Guolin Yang ${ }^{1,3}$, Chuanyin Zhang ${ }^{2}$, Xuexian $\mathrm{Sun}^{3}$, Tao Liu ${ }^{1}$, and Xuwei $\mathrm{An}^{4}$ \\ ${ }^{1}$ Faculty of Geomatics, Lanzhou Jiaotong University, Lanzhou, Gansu, 730070, China \\ ${ }^{2}$ Chinese Academy of Surveying and Mapping, Beijing, 100036, China \\ ${ }^{3}$ National-Local Joint Engineering Research Center of Technologies and Applications for National Geographic State Monitoring, \\ Lanzhou, Gansu, 730070, China \\ ${ }^{4}$ Gansu Provincial Engineering Laboratory for National Geographic State Monitoring, Lanzhou, Gansu, 730070, China
}

\begin{abstract}
Periodic crustal movement are mainly caused by ocean tides and changes of atmospheric pressure. In this project, the researcher has used the spherical harmonic coefficient of the ocean tide and actual observation data to study the impact on vertical crustal deformation due to changes of oceanic tide loading from 2012 to 2017 at the northeastern margin of the Qinghai-Tibet Plateau, based on the theory of crustal load deformation. The result shows that changes in oceanic tide loading have little impact on vertical crustal deformation compared with the impact of atmospheric loading at the northeastern margin of the Qinghai. The impact range of oceanic tide loading in this region is within $\pm 3 \mathrm{~mm}$. In contrast, impact of atmospheric loading can reach $\pm 12 \mathrm{~mm}$.
\end{abstract}

\section{Introduction}

As the crust is not a rigid body, the redistribution of mass caused by changes in the ocean, atmosphere, and continental water on the earth's surface will cause surface load response and crust deformation ${ }^{[1,2]}$. The three types of loading changes are the main factors to cause crust movement, however the impact factors may differ in different regions.

The research on the impact of the loads migrating on the earth could be dated to as early 1882, when Darwin discovered that changes in atmospheric pressure would cause vertical displacement of the earth surface ${ }^{[3]}$. It has not been put into application until the emergence of various global earth monitoring methods in the past two decades, especially the invention of GPS for continuous observations, satellite gravity, etc.

The northeastern part of the Qinghai-Tibet Plateau has undergone significant environmental changes in recent decades. The observational data over the years reflect the continuous evolution of the crust in the region.

When studying the short-period changes caused by the crustal load, we don't consider the long-period structural movement. In terms of the surface load in this region, it mainly discusses oceanic tide loading, atmospheric pressure loading, and loading due to changes in land water and groundwater. In this paper, it focuses on the study of oceanic tide loading, through the observation data of weather stations and GNSS stations in the region, to quantitatively study its impact on the crust deformation in this regional.

\section{The relationship among oceanic tide loading, atmospheric loading and vertical crustal deformation}

\subsection{Crustal load deformation}

The earth model is the prerequisite for the study of crustal load deformation, as it directly affects the solution of the load Love number and the load Green function. The model parameters will affect the calculation accuracy of the deformation. Generally, the atmospheric pressure must be used first when calculating the atmospheric load deformation. The data is expanded by 360 -order spherical harmonics, then integrated based on the load Green's function or the load Love number. Finally, the radial and horizontal displacements of the ground surface caused by atmospheric pressure can be obtained ${ }^{[4,9]}$.The main calculations are as follows .

Assuming that the load per unit mass is evenly distributed at the poles, and the areal density satisfies the following formula:

$$
\sigma(\theta)= \begin{cases}\sigma_{0} & \theta \leq \alpha \\ 0 & \theta>\alpha\end{cases}
$$

Since the total mass is 1 , under the SNREI earth model:

$$
R^{2} \int_{0}^{2 \pi} \int_{0}^{\pi} \sigma(\theta) \sin (\theta) d \theta d \lambda=1
$$


Where , $\theta, \lambda$ are co-latitude and longitude respectively. Due to the symmetry of the earth model, the integral can be obtained:

$$
\begin{aligned}
& 2 \pi \sigma_{0} R^{2} \int_{0}^{2 \pi} \sin (\theta) d \theta=2 \pi \sigma_{0} R^{2}(1-\cos \alpha) \\
& \sigma_{0}=\sum_{n=0}^{\infty} \frac{1}{2 \pi \sigma_{0} R^{2}(1-\cos \alpha)}
\end{aligned}
$$

\subsection{The process of crustal deformation due to ocean tide loading and relevant data resources}

Ocean tide phenomena usually refer to the fluctuation of seawater in the vertical direction. The cyclic load deformation of the earth surface caused by the ocean tide can reach several decimeters at maximum in the vertical direction in coastal areas, impacting on the horizontal direction as well. When a solid tide comes, the ground rises upwards, the gravity and the stability drop. At the moment of solid tides, the tidal waves comes as well. It causes the sea water to rise sharply, imposing traction on the mountain facing the sea (with the terrain slope direction pointing to the sea). The incremental tilt of the ground points towards the ocean, leading to reduced stability of the mountain facing the sea. Baker (1995) showed that the impact of ocean tidal loads on the vertical deformation of the Newlyn area in the United Kingdom could reach up to $12 \mathrm{~cm}$; Dragert (2000) pointed out that the impact could reach $8 \mathrm{~cm}$ in the Holberg area off the coast of Canada; Jentzsch (2000) analyzed that the tidal load deformation of GPS stations along the coast of Greenland Island could reach $10 \mathrm{~cm}$. This abnormal phenomenon arose mainly attributed to Greenland Island, as verified with measured data.

For coastal areas, the interaction of the solid tide and the ocean tide are superimposed before and after the occurrence of the spring tide; the FES2004 ocean tide spherical harmonic coefficient model is used to estimate the impact due oceanic tide loading in the inland areas covered in this research.

The range of latitude and longitude selected in this paper is $100^{\circ} \sim 104^{\circ} \mathrm{E}, 35.0^{\circ} \sim 39.0^{\circ} \mathrm{N}$. Gansu Gaolan GSGL, Gansu Lanzhou GSLZ, Gansu Minqin GSMQ, Gansu Jingtai GSJT stations are selected for analysis and research.

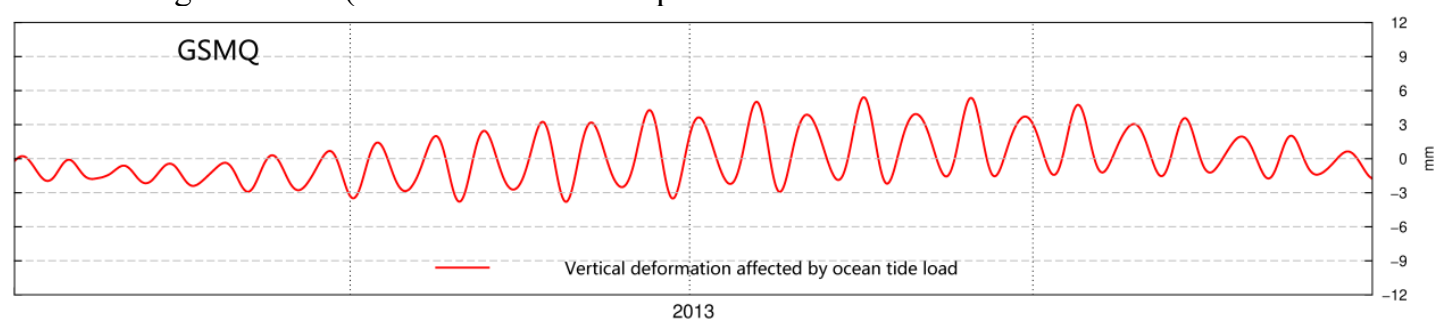

Figure 1. The vertical influence of the crust caused by the daily ocean tidal load of GSMQ station in 2013

Figure 1 shows the vertical influence of the crust caused by the daily ocean tidal load of one station in 2013 calculated by the FES2004 ocean tidal spherical harmonic coefficient model.

Comparison is made with changes in atmospheric loading simutaneously. Atmospheric loading deformation refers to the non-structural crustal deformation caused by the redistribution of atmospheric mass and changes in atmospheric pressure. Darwin (1882) first used a simple model to calculate it, and believed that changes in atmospheric pressure could cause a change in the earth surface by several centimeters. The atmospheric pressure on the earth's surface is not constant, but varies within a range of about 20-50 mbar (Magie, 1963).

The air pressure data used for comparison is obtained from the observation data of weather stations, particularly from China Meteorological Data Network. The regional GNSS monitoring data is obtained from the environmental monitoring network of mainland China. Besides, analysis data from the European Centre for Medium-Range Weather Forecasts (ECMWF) is also used.

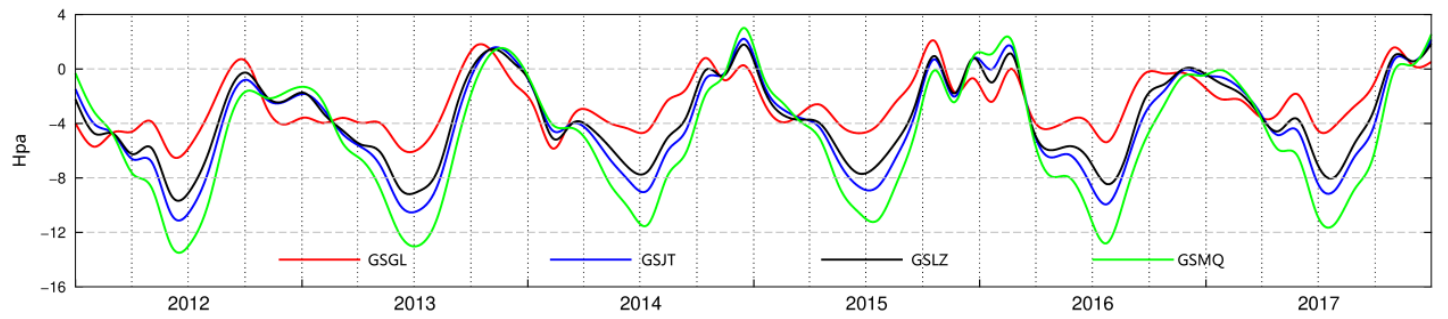

Figure 2. Time Series Change of Atmospheric Pressure at GNSS stations from 2012 to 2017

\subsection{Data observation through GNSS and its characteristics}

GSGL, GSLZ, GSMQ, and GSJT stations within the range of latitude and longitude are selected for data 
analysis. The change process of some stations is shown in Figure 3.

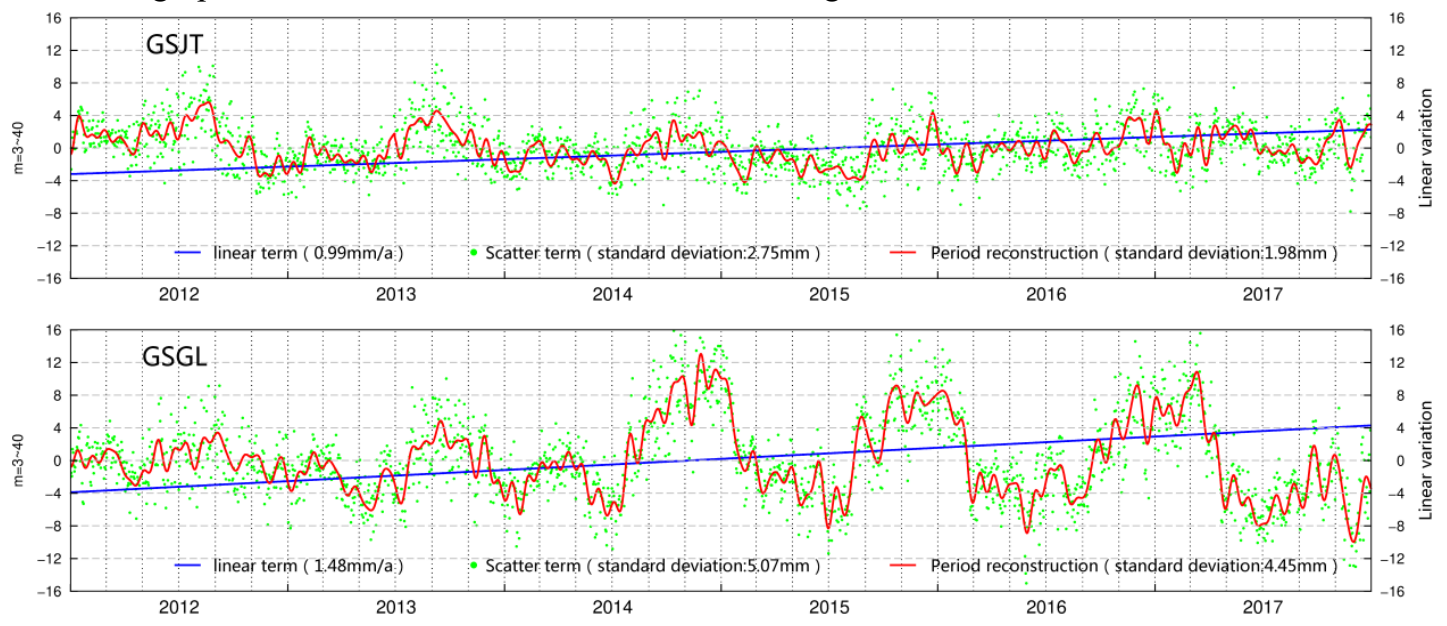

Figure 3. Time Series Change of Height at GNSS Stations

As shown in Figure 3, it is discovered that the scatter items from 2012 to 2017 are generally stable; the fitting curve after cycle reconstruction is accurately fitted to the scatter items; the overall linear change in 6 years is relatively stable. From the statistics, it can be concluded that the change rate of the ground height at GSMQ station is about $-1.98 \mathrm{~mm} / \mathrm{a}$, and the change rate of ground height at GSLZ station is about $-2.91 \mathrm{~mm} / \mathrm{a}$. Besides, the change rate of the ground height at GSJT station is about $0.99 \mathrm{~m} / \mathrm{a}$, and the change rate of ground height at GSGL station is about $1.48 \mathrm{~mm} / \mathrm{a}$. More data calculations and statistics show that, with the Qilian Mountains on the northeast side of the Qinghai-Tibet Plateau as the boundary, the change rate of land height in the Qinghai-Tibet Plateau and Qaidam Basin is much lower than that of the adjacent Loess Plateau and Inner Mongolia Plateau.

\section{The relationship between temporal and spatial changes in ocean tide and atmospheric pressure and GNSS vertical displacement and ground gravity}

With a comprehensive comparison of the relationship between the vertical deformation of ocean tide load, atmospheric pressure, vertical crustal deformation, and normal gravity back calculated from equivalent water height from 2012 to 2017, it shows that atmospheric pressure changes have obvious correlation with vertical crustal deformation and ground gravity, demonstrating remarkable changes on the basis of per year cycle. As shown in the figure, there are obvious correlations among atmospheric pressure, vertical crustal deformation, and ground gravity changes. With the increase or drop of atmospheric pressure, vertical deformation drops or increases correspondingly, as the two demonstrate opposite changes.
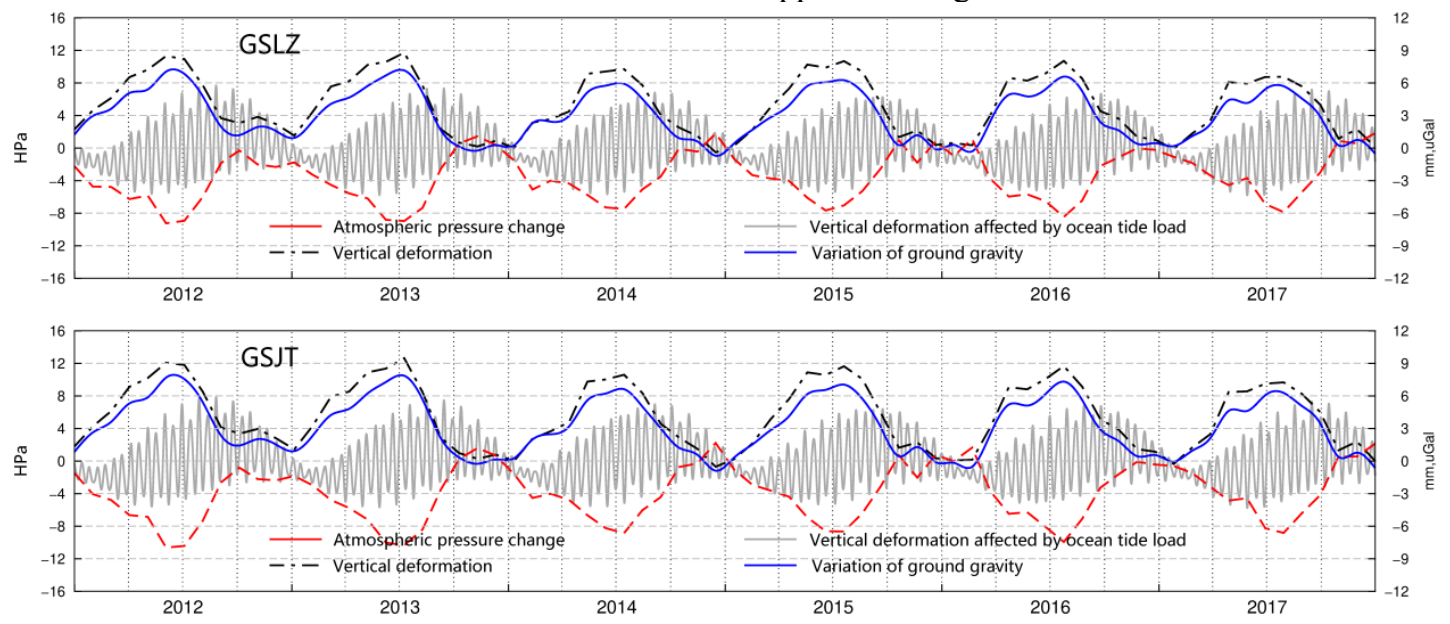

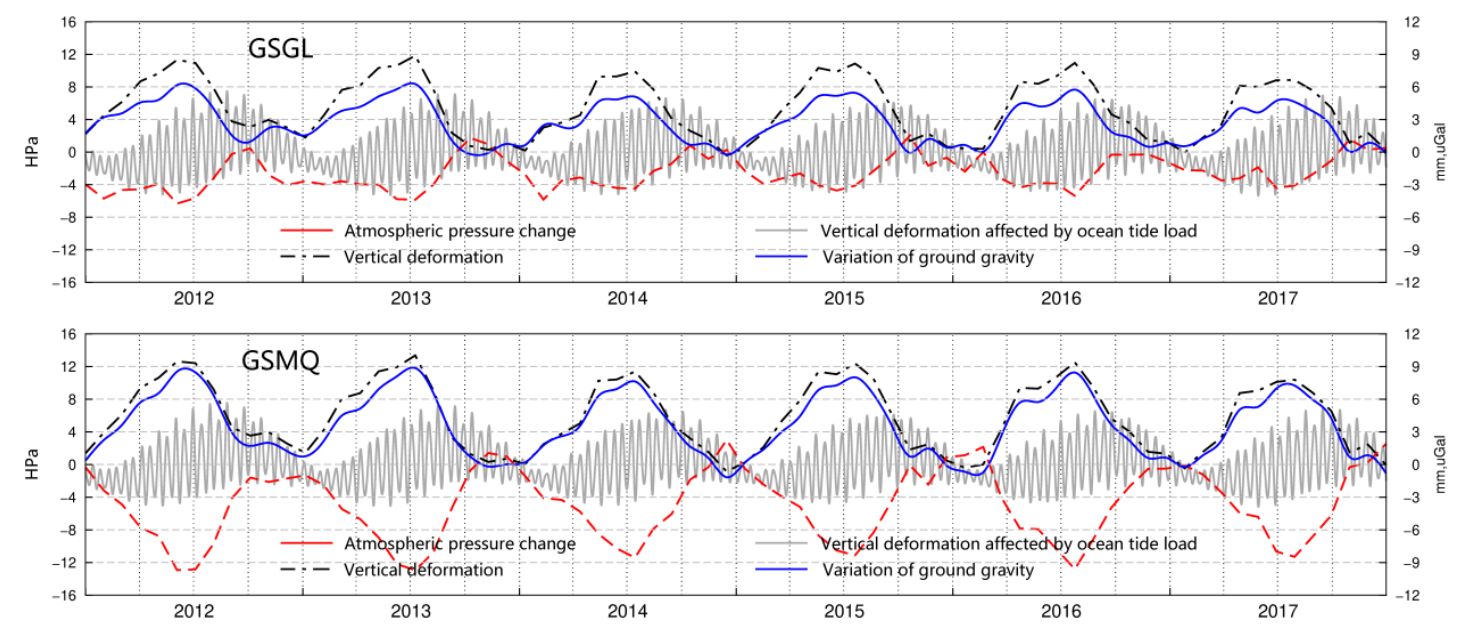

Figure 4. Time Series Change of Vertical Deformation affected by ocean tide load, Atmospheric Pressure, Vertical Deformation and Normal Gravity at GNSS Stations

The left side of the figure is marked with the atmospheric pressure change value, and the right side is the vertical deformation and ground gravity change. The influence of the atmosphere on the vertical deformation of the crust in the region can be divided into the northeastern margin of the Qinghai-Tibet Plateau and the Qilian Mountains. The annual influence on the QinghaiTibet Plateau is the smallest, about $6.1 \mathrm{~mm}$. In the northeastern part of the dividing line, the annual change range has increased significantly, reaching $12.2 \mathrm{~mm}$.

The oceanic tide loading also shows a cyclical change, but its impact on the vertical deformation of the surface is smaller than that of the atmospheric loading. Atmospheric pressure changes have strong correlation with vertical crustal deformation and ground gravity, demonstrating remarkable changes on the basis of per year cycle. Atmospheric pressure is low in summer and high in winter; the crust rises in summer and falls in winter; ground gravity increases in summer and decreases in winter. Crust demonstrates annual cyclic vertical crustal deformation, with the amplitude of the regional deformation between $5 \mathrm{~mm}$ and $12 \mathrm{~mm}$.

\section{Conclusions}

In this region, oceanic tide loading has little impact on the vertical crustal deformation. Relatively speaking, the change of atmospheric pressure distribution is the main factor to cause the vertical crustal deformation. The continuous GNSS monitoring station can observe the change process of the crust affected by the load. From the calculation of the research area $\left(35^{\circ} \sim 39^{\circ} \mathrm{N}\right.$, $100^{\circ} \sim 104^{\circ} \mathrm{E}$ ), it can be concluded that the impact of atmospheric loading in this region is periodical, as illustrated in the following.

(1) Oceanic tide loading has little implications in the inland area, demonstrating an annual change of $3 \mathrm{~mm}$. Atmospheric loading is the major impact factor in this region, with an annual change up to $12 \mathrm{~mm}$. Both demonstrate cyclic changes. Atmospheric loading is the major environmental load factor. As shown from the statistics from 2012 to 2017, it demonstrates remarkable cyclic changes on annual basis. Compared against the annual average ( generally referring to Spring and Autumn), atmospheric loading is slow in Summer but high in winter while the crust rises in Summer but falls in winter, showing cyclic changes.

(2) The impact of atmospheric loading differs greatly in the region. The annual changes of atmospheric loading drops gradually with increase of the sea level. The two sides at the northeastern margin of the Qinghai-Tibet Plateau and the Qilian Mountains exhibit sharp difference in the annual changes subject to alteration of season. Atmospheric loading plays a dominant role in summer and winter, while crust deformation changes remarkably when the seasons alternate.

\section{Acknowledgments}

Upon the completion of my thesis, I would like to express my deepest gratitude to my mentor Professors Zhang Chuanyin and Sun Xuexian for their continual guidance and encouragement. I would also like to express my earnest thanks to National Nature Science Foundation of China, by which all the experiments of the study have been funded. My gratitude also goes to my beloved family and colleagues for their encouragement and support.

This work was funded by the National Key Research and Development Program of China(2016YFC0803106), the National Natural Science Foundation of China (41764001,41761088), LZJTU EP 201806.

\section{References}

1. Deformation of the earth by surface loads. Farrell WE. Reviews of Geophysics . 1972

2. Global Modeling of Land Water and Energy Balances. Part I: The Land Dynamics (LaD) Model. P C D Milly,A B Shmakin. Journal of Hydrometeorology . 2002

3. Surface mass redistribution inversion from global GPS deformation and Gravity Recovery and Climate Experiment (GRACE) gravity data (DOI 
10.1029/2004JB003556). J Kusche,E J O Schrama. Chinese Journal of Geophysics . 2005

4. Anatomy of apparent seasonal variations from GPS derived site position time series. Dong D,Fangn D,Bock Y,et al. Chinese Journal of Geophysics . 2002

5. Vertical deformations from homogeneouslyproces sed GRACE and global GPS long-term series. Tes mer V,et al. Journal of Geodesy . 2011

6. Self-consistency in reference frames, geocenter definition, and surface loading of the solid Earth. Blewitt G. Chinese Journal of Geophysics . 2003

7. Inversion of Earth's changing shape to weigh sea level in static equilibrium with surface mass redistribution. BLEWITT G,CLARKE P. Chinese Journal of Geophysics . 2003

8. IERS Technical Note 36. IERS Convention 2010 . 2010

9. High resolution spherical and ellipsoidal harmonic expansions by Fast Fourier Transform . Christian Gruber,Oleh Abrykosov. Studia Geophysica et Geodaetica . 2014 